\title{
OPINION
}

\section{Death and injury from motor vehicle crashes: a public health failure, not an achievement}

\author{
E D Richter, P Barach, E Ben-Michael, T Berman
}

Hebrew

University-Hadassah

School of Community

Medicine and Public

Health, Unit of

Occupational and

Environmental

Medicine, Betts Injury

Prevention Center,

Jerusalem, Israel

E D Richter

E Ben-Michael

T Berman

Department of

Anesthesiology and

Critical Care, Pritzker

University of Chicago

School of Medicine,

Chicago, USA

P Barach

Correspondence to: Dr Elihu Richter, Unit of Occupational and

Environmental Medicine,

Hebrew University-Hadassah

Medical School, Jerusalem

91120, Israel
Elir@cc.huji.ac.il

In 1999, the Centers for Disease Control (CDC), the United States government's leading agency in public health, published a document entitled Motor Vehicle Safety: A 20th Public Health Achievement. ${ }^{1}$ We suggest, however, that the record shows a failure, not an achievement.

The document claims that systematic motor vehicle safety efforts, which began in the United States in the 1960 s, were responsible for the enormous reduction in the risks for deaths from road injury. This claim is accompanied by a graph that shows the steady drop in death per vehicle miles traveled (D/VMT) from $18 / 100$ million in 1925 to $1.7 / 100$ million in 1997, a $90 \%$ decrease (fig 1). The document emphasizes that this drop occurred despite a 10 -fold increase in miles traveled, a sixfold increase in the number of drivers, and an 11-fold increase in the number of motor vehicles. What, then, is wrong with the CDC's conclusions?

In 1998, the absolute number of road deaths in the United States was 41471 but since 1991 there have been no drops in the absolute number of road deaths/year, and between 1992-98 the D/VMT fell only slightly, from 1.7

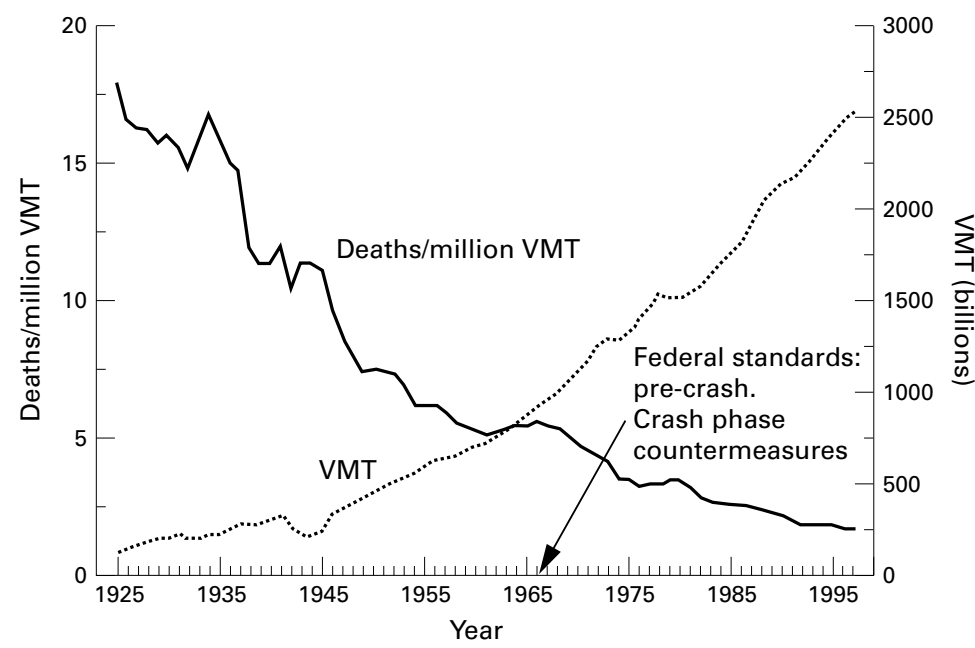

Figure 1 Motor vehicle related deaths/million miles traveled (VMT) and annual VMT, by year, United States 1925-97. Most of the drop in risk for deaths from road injury preceded 1966, when the United States initiated motor vehicle safety efforts. (Source: USCDC. Motor Vehicle Safety: a 20th Century Public Health Achievement 1999;48(18):369-74.)

\author{
Box 1: Countermeasures \\ - Increased mass/volume. \\ - Better seat belt designs/child restraints. \\ - Improved fireproofing of fuel tanks. \\ - Seat belt laws. \\ - Burstproof latches. \\ - Collapsible steering wheels. \\ - Shatterproof window panes. \\ - Padded dashboards. \\ - Non-protrusive accessories. \\ - Reinforced passenger cabins. \\ - Rear underride absorbers for trucks. \\ - Energy absorbing fixtures. \\ - Airbags. \\ - Drink driving legislation. \\ - Truck safety standards. \\ - Updated road design standards. \\ - Congestion, lower speeds, and risk.
}

to $1.6 .^{2}$ Large drops in D/VMT in earlier decades should not divert attention from the subsequent failure to reduce deaths in absolute numbers.

\section{Congestion, lower speeds, and risk}

The CDC document ignores the fact that drops in D/VMT have been occurring worldwide, since the 1920s. ${ }^{3}$ Worldwide, the inverse relationship between increase in VMT and decrease in D/VMT is shown by cross sectional $^{4}$ as well as longitudinal studies. ${ }^{5}$ Emptier roads have higher case fatality rates and D/VMT (Netherlands) ${ }^{4}$; cities with lower rates of car ownership have higher death risks/ vehicle and case fatality rates (Israel) ${ }^{6}$; and there is a strong inverse relationship between D/VMT and population density and road congestion. ${ }^{7}$

Some $75 \%$ of the drop in D/VMT preceded the late 1960s, when following Ralph Nader, ${ }^{8}$ the federal government first began to set standards for a highly effective set of pre-crash and crash phase countermeasures (see box 1).

The fact that D/VMT varies inversely with increased VMT in cross sectional as well as longitudinal comparisons undermines the hypothesis ${ }^{9}$ that global time trends in introducing countermeasures are the major explanation for the decrease in D/VMT over time. There is a need to identify factors other than countermeasures in contributing to this fall. 
We believe the universality of the strong inverse association between risk and exposure is mainly due to increases in traffic congestion. Everywhere, in the United States, Europe, and the great megacities of Asia, Latin America, and Africa, most of the increase in VMT and congestion occurs in and around large cities and their surrounding areas during rush hours. These are periods when mean and maximum traffic speeds approach standstill, and case fatality falls, as does D/VMT - without the help of any public health policy or countermeasures. Much of the credit for the public health "achievement" comes from the failure to provide rapid travel during peak hours of use for most vehicles. Thus VMT is massively inflated. No one gets killed in a traffic jam.

In road injury epidemiology, kinetic energy is the pathogen, ${ }^{10}$ and risk for injury and severity are predicted by the combined effect of mass and speed derived from Newtonian laws of motion and energy. Crash, injury, and death tolls rise in proportion to the first, second, and fourth power respectively of the ratio of increase in average speeds of travel. ${ }^{11}$ A $10 \%$ increase in travel speeds produces a $43 \%$ rise in case fatality. ${ }^{12}$ Case fatality-the probability of death - among occupants of light vehicles colliding with heavy vehicles is extremely high. ${ }^{13}$ These empirically validated relationships mean that small increases in speed translate into large increases in deaths. We affirm that in recent years in the United States the fall in baseline risks with increased congestion has concealed the full contribution of raised speed limits and travel speeds to increasing deaths.

\section{The soccer field is tilted downwards}

Because the trend for risk in D/VMT is falling, ${ }^{3}$ use of D/VMT to "correct for" increases in exposure conceals trends revealing increases in absolute numbers of deaths. It follows that before-after studies based on correction for exposure, when using a time window of several years, are analogous to playing on a soccer field tilted downward. When the players kick the ball downward we overestimate the effectiveness of the kick. Because the background risk of $\mathrm{D} / \mathrm{VMT}$ is tilted downwards as a result of congestion, we make the same mistake in estimation if we use this parameter alone to monitor "progress" in reducing road deaths.

From 1988 to 1992, D/VMT fell 26\%from 2.3 to 1.7 , or, $5 \%$ per year. But from 1992 to 1998 , the D/VMT only fell by $6 \%$-from 1.7 to 1.6 - that is, less than $1 \%$ per year, despite a $39 \%$ reduction in alcohol related deaths since 1982. ${ }^{12}$ The CDC graph (fig 1) shows a drop in the risk for D/VMT- $8 \%$ to $10 \%$ per decade since 1925 , or $1.3 \%$ per year, although the drops were much larger in absolute terms. ${ }^{1}$

\section{Forgetting speed}

What has offset the effects of countermeasures in lowering road deaths? If the death toll in the
United States is in the range of 40000 victims per year, a downward tilt in D/VMT of some $1.3 \%$ per year would conceal an increase in death tolls of some 520 persons per year. How appropriate is the use of a parameter to monitor "progress" if it buries - both literally and figuratively - such a large increase in deaths?

Both the CDC, as well as the review by Rivara et $a l,{ }^{14}$ ignore the contribution of reduced speed limits and new systems for speed control in producing immediate, large and sustained reductions in deaths and injuries, and, of course, the reverse. Two decades of research have made the case for a direct causeeffect relationship between lower speed limits and reduced death tolls. These were seen first during the energy crisis in the 1970 s, documented in a classic United States government study, ${ }^{15}$ not cited in the CDC document, and later work in Sweden. ${ }^{16}$ Higher death tolls followed higher speed limits in the 1980s and $1990 \mathrm{~s},{ }^{17}{ }^{18}$ whereas recently lower death tolls in the United Kingdom followed the introduction of speed cameras. ${ }^{19}$ Thus, we suggest that higher speed limits and travel speeds are the most plausible explanation for the fact that deaths are no longer declining in the United States. ${ }^{20}$ The United States Department of Transportation has estimated that speed associated crashes account for $8710(21 \%)$ of the 41474 road deaths in $1998 .^{2}$ Risk assessments from Germany have determined that a nationwide policy of speed control would prevent some $2000(22 \%)$ of the 9000 road deaths in that country each year (German Society for Environmental Medicine, Position Paper 1997; R Frentzel-Beyme, personal correspondence, 1998). Yet, the word "speed" does not appear even once in the CDC document.

How can we estimate the effect of measures that result in increased speed of vehicle travel? In our view, their impacts, in both the literal and figurative sense, can best be measured by tracking trends in the case fatality rate- the risk of death among all those injured. Case fatality is independent of exposure-VMTand specifically measures the impact of crash phase events. The case fatality rate (deaths/ 1000 vehicles) in 1988 was $13.6 / 1000$, fell to 12.4 in 1992 , but then rose to 13.1 in $1998 .^{2}$

Calculations based on before-after comparisons of case fatality give a direct measure of deaths from changes in speed of impact, using the equation in the box below $(\mathrm{CFR}=$ case fatality rate).

Application-If 39250 were killed in 1992 and CFR (1998) was 13.1 and CFR (1992) was 12.4, then 2215 deaths could be attributed to the mean rise in speeds of impact.

The observed increase in deaths was 41 471-39 $250=2221$, or $5.7 \%$, despite the $5.9 \%$ decrease in D/VMT from 1.7 to 1.6 . In other words, $25.3 \%$ of the 8710 deaths attributed by the National Highway Traffic Safety Administration to speeding result from

$\Delta$ deaths $(\mathrm{n})$ from $\Delta \mathrm{V}($ impact $)=$ deaths $($ before $) \times(\mathrm{CFR}($ after $)) /(\mathrm{CFR}($ before $))$ 
increases in speed of impact in 1998 compared to 1992, despite improved countermeasures. These figures, and the estimate above that "correcting for exposure" conceals some 520 deaths/year suggest that the estimate of Farmer et al of 400-500 additional deaths per year from increased speed limits in the United States may less than a quarter of the true number. ${ }^{21}$ Indeed, Farmer's data show that a rise in deaths on roads other than interstates was actually reversed when "corrected for" increased VMT.

We have used time trends in case fatality to track the long term effects on road deaths after increased speed limits. ${ }^{22}$ These effects are concealed by countermeasures and congestion.

We have also used models based on kilometers traveled, increased speeds, speed spillover, and case fatality to predict the number of deaths expected from building new high speed roads. ${ }^{23}$

\section{Vision Zero: reducing the number, not only the rate}

Sweden has announced a policy of Vision Zero for road deaths. ${ }^{24}$ This policy declares that a target of no road deaths should be the ethical norm and ultimate goal of transport policy. The World Health Organization-Europe and the British government have set a target of reductions of $30 \%$ and $40 \%$ respectively in road deaths for the next decade. ${ }^{25}{ }^{26}$ For the United States, a target of $40 \%$ reduction means less than 24000 deaths/year.

A rapid reduction by $50 \%$ is already achievable. Since 1990, Victoria, Australia, has reduced deaths by approximately one half through the introduction of a province-wide network of speed cameras. ${ }^{27}$ In the United Kingdom there has been a reduction by $40 \%$ in deaths in the last decade attributed to speed cameras. $^{28}{ }^{29}$ These networks are sustainable because their revenues make them self financing.

\section{Deaths, D/VMT, and the ethics of injury epidemiology}

In recent years, there are some $1000000 \mathrm{road}$ deaths per year worldwide. ${ }^{30}$ How do we measure progress in preventing deaths from transportation? The use of D/VMT as the criterion implicitly endorses an ethically problematic paradigm that weighs the benefits of transportation-time saved-against the losses - deaths and injuries. If we use absolute numbers, we hold that individuals should not be sacrificed for collective benefits. ${ }^{31}$ It follows that to protect public health, we need comparisons of risks for deaths/person-mile or deaths/ ton-mile from alternative modes of transport. and not merely D/VMT from a single mode. The use of time trends in D/VMT within one mode of travel precludes examining alternative strategies based on shifts to public transport, a mode usually with much lower risks. The use of D/VMT rather than numbers of dead as a measure of progress conceals a public health failure in injury prevention.

1 US Centers for Disease Control. Achievements in public health, 1990-1999. Motor vehicle safety: a 20th century public health achievement. MMWR Morb Mortal Wkly Rep 1999;48(18):369-74.

2 US Department of Transportation, National Highway Traffic Safety Administration. Traffic safety fact sheet. Washington, DC: NHTSA, 1998 (www.nhtsa.dot.gov).

3 Smeed RJ. Variations in the pattern of accident rates in different countries and their causes. Traffic Engineering and Control 1968;10:364-71.

4 Van Beeck EF, Mackenback JP, Looman CWN, et al. Determinants of traffic accident mortality in the Netherlands: a geographical analysis. Int f Epidemiol 1991;20:698-706.

5 Posada J, Ben-Michael E, Herman A, et al. Death and injury from motor vehicle crashes in Colombia. Fournal of the Pan American Health Association 2000;79:88-91.

6 Ben David G, Elharar A, Reingold S, et al. Speed control and road injuries: a pilot project in a high risk city. Jerusalem: Center for Injury Prevention, 1999.

7 Cites study by the National Safety Council, 2000. The Boston Globe 26 August 2000: A10.

8 Nader R. Unsafe at any speed; the designed-in dangers of the american automobile. New York: Pocket Books, 1966.

9 Beenstock M, Gafni D. Globalization in road safety: explaining the downard trend in road accident rates in a single country (Israel). Accid Anal Prev 2000;32:71-84.

10 Robertson LS. Injury epidemiology. Oxford: Oxford University Press, 1992.

11 Nilsson G. The effect of speed limits on traffic accidents in sweden. VTI Report 68. Linkoping, Sweden: National Road and Traffic Research Institute, 1982: S-58101, 1-10.

12 Joksch $\mathrm{H}$. Velocity change and fatality risk in a crash: a rule of thumb. Accid Anal Prev 1985;17:155-70.

13 Evans L. Traffic safety and the driver. New York: Van Nostrand Reinhold, 1991.

14 Rivara FP, Grossman DC, Cummings P. Injury prevention: First of two parts. N Engl f Med 1997337:543-8

15 National Research Council. $55 \mathrm{mph}$ : a decade of experience. Washington, DC: National Research Council, 1984

16 Nilsson G. Reduction in the speed limit from $110 \mathrm{kph}$ to $90 \mathrm{kph}$ during summer 1989. VTI report 358. Sweden: Transport Institute, 1990.

17 Insurance Institute For Highway Safety. Limits up, speeds up, deaths up. Status Report 1997;32(8):1-4.

18 Garber S, Graham JD. The effect of the new $65 \mathrm{mph}$ speed limit on rural highway fatalities: a state-by-state analysis. Accid Anal Prev 1990;22:137-49.

19 West R. The effect of speed cameras on injuries from road accidents. BMF 1998;316:5-6.

20 Insurance Institute for Highway Safety. Motor vehicle deaths unchanged overall but important differences still apparent. Status Report 1998;33(9):4-5.

21 Farmer CM, Retting RA, Lund AK. Changes in motor vehicle occupant fatalities after repeal of the national maximum speed limit. Accid Anal Prev 1999;31:537-44.

22 Richter ED, Barach P, Krikler S, et al. Speed kills: effect of $100 \mathrm{kph}$ speed limit on road deaths in Israel (abstract). Israel Statistical Society May 1997.

23 Ginsberg G, Fletcher E, Ben-Michael E, et al. (1997) How many shall live, how many shall die? Deaths resulting from the Trans-Israel Highway and alternatives: a risk assessment. World Transportation Policy and Practice 1997;3:4-10.

24 Belin MA, Johansson R, Lindberg J, et al. The Vision Zero and its consequences in safety and the environment in the 21 st century. Proceedings of the 4th International conference on safety in the environment in 21st century. Tel Aviv, Israel,

25 World Health Organization. Injuries and world health report. Geneva: WHO, 1999 (www.who.int.home).

26 Department of the Environment, Transport, and the Regions. The government's road safety strategy and casualty reduction targets for 2010. London: DETR, 2000.

27 McDermott J, Cordner SM, Temanyne AB. Evaluation of the medical management and preventability of death in 137 road traffic fatalities in victoria australia: an overview. $\mathcal{f}$ Trauma 1996;40:520-35.

28 British Road Federation (http://www.brf.co.uk).

29 Department of Environment, Transport and Regions (http://detr.gov.uk).

30 Whitelegg J. Transport for a sustainable future: the case for Europe. London: Belhaven Press, 1993.

31 Richter ED, Barach P, Berman T, et al. Extending the boundaries of the Declaration of Helsinki: a case study of an unethical experiment in a non-medical setting. $7 \mathrm{Med}$ Ethics 2001;27:126-9. 